\title{
Histopatologia das lesões de Brachyplatystoma spp. (Pisces: Siluriformes) por Nomimoscolex piraeeba Woodland, 1934 (Cestoda: Proteocephalidea)
}

\author{
Histopathology of lesions in Brachyplatystoma spp. (Pisces: \\ Siluriformes), due to Nomimoscoles piraeeba Woodland, 1934 (Cestoda: \\ Proteocephalidea)
}

Amilcar Arandas Rego, * Guido V. Schaeffer*

\section{Resumo}

Duas espécies de peixes, Brachyplatystoma filamentosum e B. flavicans, da região Amazônica foram estudadas para parasitas e achados histopatológicos. Ambas as espécies mostravam-se parasitadas pelo cestóide proteocefalídeo, Nomimoscolex piraeeba. Em B. filamentosumforam encontradas lesões, de aspecto tumoral, descritas e comparadas com o que foi observado na outra espécie de peixe, B. flavicans, cuja patologia apresentou-se mais discreta. É discutido o papel das glândulas frontais, presentes no escólex do verme, na patologia resultante no intestino do hospedeiro.

Palavras-chave: ictiopatologia; cestóide proteocefalídeo; Nomimoscolex piraeeba; peixe amazônico.

\section{Introdução}

Em recente excursão na região de Itacoatiara, rio Amazonas, coletou-se material de peixes que apresentavam lesõès no intestino.

No laboratório foi feita a identificação dos helmintos e estudada a patologia resultante, objeto deste estudo.

Além da descrição da histopatologia nos peixes, discutiuse o possível papel patológico desempenhado pelas chamadas glândulas frontais do parasita, identificado como Nomimoscolex piraeebaWoodland, 1934.

\section{Material e métodos}

As espécies Brachyplatystoma filamentosum(Licht.) e $B$. flavicans (Castelnau) são peixes comuns na região Amazônica. Os oito exemplares analisados para o presente estudo foram coletados na localidade de Itacoatiara, Amazonas. Os peixes foram dissecados, retirados os seus intestinos e colocados em placas de Petri com solução salina. O intestino foi aberto longitudinalmente e examinado para verificar a presença de parasitas. Os cestóides foram fixados in situ com formol a 4\% aquecido até a ebulição; posteriormente, no laboratório, foi feita a triagem dos vermes. Tecidos que apresentavam lesões, além de outros sem lesões aparentes, foram fixados pelo formol neutro a $4 \%$ e conservados separadamente.

O material processado para histopatologia foi seccionado com 5 micra e corado pelos métodos da Hematoxilinaeosina e pelo PAS.
Os cestóides foram corados pelo carmin alcoólico ou pela Hematoxilina de Delafield e montados em bálsamo do Canadá para estudo microscópico.

Fotografias de cortes de tecidos foram obtidas em microscópio Leitz Confocal LSA 410 e em microscópio Zeiss.

\section{Resultados}

\section{Lesões em Brachyplatystoma filamentosum}

Os cortes de intestino mostraram lesão inflamatória com crescimento tumoral, resultante de espessos envoltórios de leucócitos mononucleares ao redor dos corpos parasitários. Constatamos células gigantes, tipo corpo estranho, e, em cortes corados pelo PAS, abundantes células mononucleares com grânulos citoplasmáticos carminados, sugérindo mastócitos. Na área da lesão havia desaparecimento das pregas intestinais, das criptas e do epitélio de revestimento. O plano muscular e a serosa estavam rompidos, e o tecido fibroso, proliferado. Os vasos sangüíneos mostravam-se dilatados e congestos. Partes do corpo parasitário exibiam graus variáveis de degeneração, com transformação em material eosinofílico. A resposta inflamatória abrangia as estruturas vizinhas.

\section{Lesões em Brachyplatystoma flavicans}

Em um dos peixes, o parasita suscitou reação inflamatória que comprometia a mucosa e a submucosa, com infiltrado de leucócitos mononucleares; as pregas intestinais mostravam-se avultadas, rompidas apenas onde ha-

\footnotetext{
* Pesquisador I-A do CNPq. Departamento de Helmintologia, Fundação Oswaldo Cruz, Caixa Postal 926, 20010-900, Rio de Janeiro, Brasil.
} 


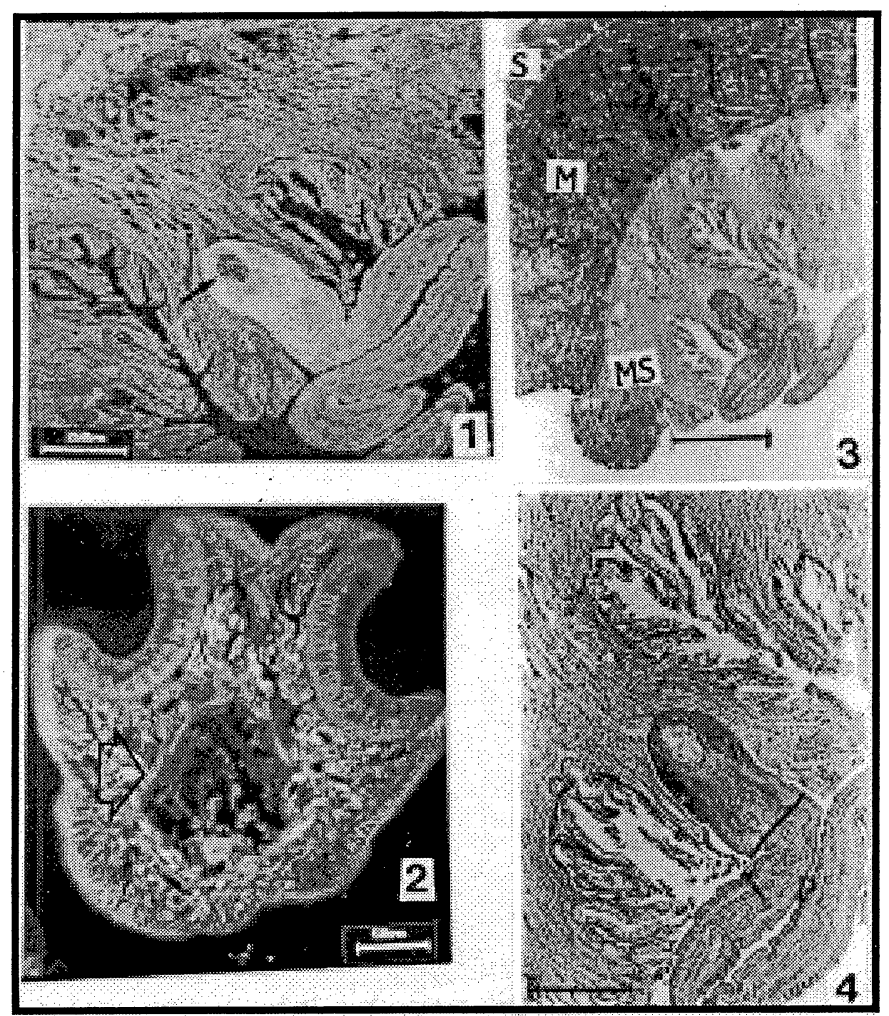

Figura 1: Corte de intestino de Brachyplatystoma filamentosum com o parasita Nomimoscolex piraeeba in situ. Note a glândula apical no escólex do verme (seta).

Figura 2: $N$. piraeeba; corte do escólex com glândula apical (seta). Figura 3: Corte de intestino de $B$. filamentosum. Observa-se o parasita com a extremidade anterior penetrando a mucosa. $S=$ serosa; $M=$ muscular; $\mathrm{MS}=$ mucosa e submucosa.

Figura 4: corte de intestino de $B$. filamentosum, interessando a mucosa e a submucosa. Observa-se infiltrado inflamatório e descamação do epitélio de revestimento. $\mathrm{P}=$ parasita.

via penetração do parasita; não havia lesão de aspecto tumoral. $O$ infiltrado difuso era predominantemente leucocitário mononuclear. Os vasos, de maneira geral, estavam dilatados. O epitélio, tanto das vilosidades como das criptas, apresentava graus discretos de exfoliação. Os planos musculares, embora espessados, não exibiam infiltrado leucocitário. Não foi observada fibrose dos tecidos.

Em outro dos peixes examinados desta espécie, observou-se uma perfeita adaptação do corpo do parasita às vilosidades eàs criptas intestinais. Havia discreto infiltrado leucocitário mononuclear na submucosa e na serosa, sem maiores alterações.

\section{Discussão}

O cestóide proteocefalídeo Nomimoscolex piraeba Woodland, 1934 é freqüente em ambas as espécies de Brachyplatystoma. Essa espécie foi redescrita por Rego (1991), que chamou atenção para a presença de glându-

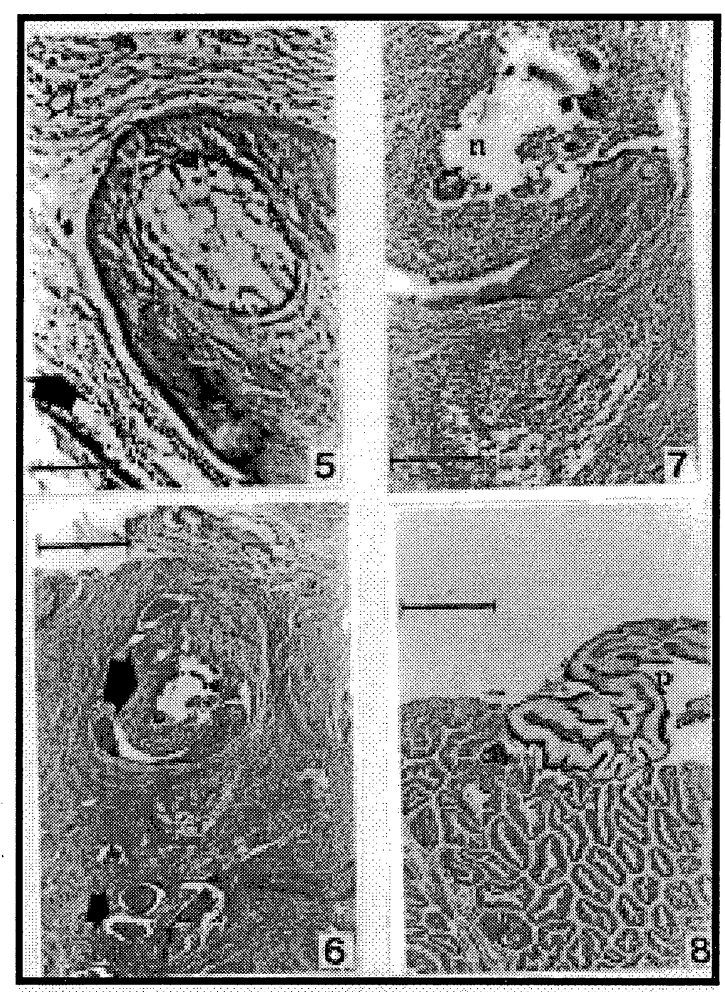

Figura 5: Corte de intestino de B. filamentosume extremidade anterior do parasita. Notar infiltrado leucocitário (setas).

Figura 6: Corte de intestino de B. filamentosum. Observam-se alterações inflamatórias encontradas na área de aspecto tumoral e secções do corpo do parasita em vários estados de degeneração (setas).

Figura 7: Corte de intestino de B. filamentosum, ampliado. Observase área necrótica $(n)$ com densos acúmulos leucocitários.

Figura 8: Corte de intestino de B. flavicans. Observam-se numerosas criptas e o parasita $(P)$ adaptado a elas. Não há alterações visíveis.

las na região apical do escolex, glândulas estas conhecidas por apicais ou frontais. Elas exercem ação importante durante a fase larvar, mas nada se sabe sobre seu papel em vermes adultos nas espécies da Ordem Proteocephalidea. Para alguns autores poderiam ser glândulas de penetração, ocasionando dessa forma uma patologia maior do que, por exemplo, a de espécies desprovidas de tais estruturas, mas para outros autores, elas serviriam apenas para facilitar a adesão ao hospedeiro. De qualquer modo, é provável que a secreção destas glândulas possa atuar como forte irritante dos tecidos, contribuindo para a ação inflamatória, e que o nódulo resultante seja parte da reação inflamatória do peixe (Hayunga, 1979). O pequeno número de peixes examinados não pode esclarecer a razão pela qual o Brachyplatystoma filamantosum mostrou reação mais acentuada ao parasita que a espécie $B$. flavicans. De qualquer modo, maiores observações fazem-se necessárias para esclarecer o problema. 


\begin{abstract}
The authors study the pathologic alterations in the intestine of the Amazonian fishes, Brachyplatystoma filamentosum and $B$. flavicans, caused by the proteocephalid species Nomimoscolex piraeeba. Tumoral lesions were observed in the intestine of $B$. filamentosum. The lesion, in the intestine wall of $B$. flavicans, was also inflamatory, but with a diffuse and mild pattern. The possible role of the frontal glands, of these worms species, to produce lesions at the host gut tissues was briefly discussed.
\end{abstract}

Keywords: icthyopathology; proteocephalid cestodes; Nomimoscolex piraeeba; freshwater fishes.

\title{
Agradecimentos
}

Agradecemos a Bruno Silva Vale (Depto. de Patologia da Fiocruz), pelas micrografias em microscópio Confocal, e ao Setor de Fotografia (Fiocruz) pelas microfotografias das lesões.

\section{Referências bibliográficas}

HAYUNGA, J. R. A. The structure and function of the Scolex glands of the Caryophyllid tapeworms. Proc. Helminthological Society Washington, n. 46 v. 2, p. 171 179, 1979.
REGO, A. A. Redescription of Nomimoscolex piraeeba Woodland, 1934 (Cestoda, Proteocephalidea), from the Amazon catfishes, Brachyplatystoma spp. With proposal of synonyms and invalidation of Endorchiinae and Endorchis. Memorias Instituto Oswaldo Cruz, n. 86, v. 2, p. 229-232, 1991. 